\title{
Is There a Relationship between Maximal Grip Strength and Racquetball Success? A Pilot Study
}

\author{
By Jeff S. Layton ${ }^{\dagger}$ \\ Mark DeBeliso*
}

\begin{abstract}
Grip strength has proven to have a positive effect on sports performance in which a sport implement is grasped in the hand. Racquetball athletes are constantly in search of ways to find advantages over their competition and there is a paucity of research regarding the role of grip strength and racquetball performance. Purpose: This study sought to find the relationship between maximal grip strength of the dominant hand and success (in the context of an amateur racquetball tournament) in the sport of racquetball. Methods: Racquetball tournament players were recruited to participate in the study prior to the beginning of the tournament. Each participant was asked to perform at least three maximal isometric grip strength measurement trials using a Jamar Handgrip Dynamometer and the average of the three highest grip strength readings was recorded. The participants then went on to play in their groups in the racquetball tournament at the Utah Summer Games (USG). Following the tournament, the USG racquetball organizer provided researchers with the full results of the racquetball tournament. Results: Because of the limited number of female participants in the study only the data concerning male participants was statistically analyzed. Due to the large number of sub groups in the tournament, the data were analyzed as those who finished in 1st place versus those who finished below first place. An independent t-test indicated that there was not a significant difference in grip strength between group winners and the other competitors. Discussion: Although the results of this study did not show a significant difference in grip strength between those who succeeded in tournament play and those who did not, the results are important to the overall discussion of the role that grip strength plays in racquet sports, most specifically racquetball. This data can serve as a launching point for further research regarding grip strength and racquetball. Conclusion: Within the parameters of this study, it does not appear that grip strength plays a significant role in winning and losing in racquetball tournament competition.
\end{abstract}

Keywords: Grip Strength, Racquetball, Performance

\section{Introduction}

Grip strength has been shown to have a positive effect on performance in many sports wherein a handheld implement is used (Koley \& Yadav, 2009). Racquetball requires the competitor to couple the hand with the racquet in order to strike the racquetball. Much of the research regarding racquet sports has been performed with sports other than racquetball, such as tennis. (King, Kentel, \& Mitchel, 2012; Grabiner, Groppel, \& Campbell, 1983; Missavage, Baker, \& Putnam, 1984). Grip strength has long been used to measure muscular strength (Rodrigues Matsudo, Matsudo, de Rezende, \& Raso, 2015) and research findings have shown that grip correlates with physical fitness measures such as; body composition, energy expenditure, aerobic power, lower

\footnotetext{
${ }^{\dagger}$ Southern Utah University, Department of Kinesiology and Outdoor Recreation, USA.

* Professor, Southern Utah University, Department of Kinesiology and Outdoor Recreation, USA.
} 
limb strength, sit-up performance, flexibility, speed, and agility (Rodrigues Matsudo, et al., 2015).

Many sports are played using a handheld implement such as a bat in cricket, a racquet in racquetball, or a stick in ice and field hockey. It is obvious that the ability to manipulate an instrument provided in a particular sport might highly influence an athlete's success. Grip strength may be an indicator of good performance in such sports (Koley \& Yadav, 2009).

It is reasonable to presume that a person who has a stronger grip should be able to grasp a hand held instrument with greater tightness than one with a weaker grip. In baseball, a tighter grip on the bat has been associated with greater post-impact ball velocity (Weyrich, Messier, Ruhmann, \& Berry, 1989). A faster post impact ball velocity could be the difference between a base hit and a groundout, or a home run and a routine fly out. Thus, a batter who has a stronger grip would have an advantage over batters whose grip is weaker.

In racquetball, grip strength may affect the velocity of the ball following impact. Some research has found that in sports played using a long racquet, like tennis, grip strength does not appear to make a significant difference on velocity of the ball (Missavage, Baker, \& Putnam, 1984). Conversely, other research has found that a tighter grip does result in faster ball velocity after racquet impact (Elliot, 1982). Regardless, when the length of the racquet is short, grip firmness does influence the velocity of the ball following impact with the racquet (Missavage, et al., 1984). Because grip strength can affect ball velocity when using shorter racquets (like those used in racquetball) it is possible that having a strong grip could influence how fast an athlete is able to cause the ball to travel and may likely allow a racquetball player to be more successful in competition. Specifically, greater grip strength should result in a consistently higher post-impact ball velocity. Consistently higher post-impact ball velocity should catch the opponent at a disadvantageous position more often, hence preventing them from a successful return volley. Just a few points separate many matches. The potential edge provided by higher post-impact ball velocity could be the difference between winning and losing.

Hence, the purpose of this study was to determine if a player's maximal grip strength of the dominant hand is associated with success in a competitive racquetball tournament. It was hypothesized that the participants with greater grip strength would place higher in a competitive racquetball tournament.

\section{Methods}

\section{Participants}

The Participants in this study were males $(\mathrm{n}=22)$ who were participating in the racquetball tournament in the 2016 Utah Summer Games (USG). Permission from the Institutional Review Board at Southern Utah University to use human subjects was obtained prior to any data collection. Each participant read and signed an informed consent form prior to providing any grip strength measurement. All participants were required to be participating in one or more 
of the singles racquetball groups, athletes who were only participating in the doubles tournament were not included in this study. The participants who sustained injuries that barred their completion of the tournament were also excluded from statistical analysis.

\section{Instruments and Apparatuses}

Grip strength data collection was performed during the registration period for the racquetball tournament of the USG held on the campus of Southern Utah University in Cedar City, Utah and during the first day of the tournament. The instrument used for grip strength measurements was the Jamar handgrip dynamometer (Figure 1) which is considered the gold standard for measurement of grip strength (Amaral, Mancini, \& Novo, 2012). The instrumentation was provided by the Cardiac Rehabilitation Department at Dixie Regional Medical Center in St. George, Utah.

Figure 1. Jamar Dynamometer

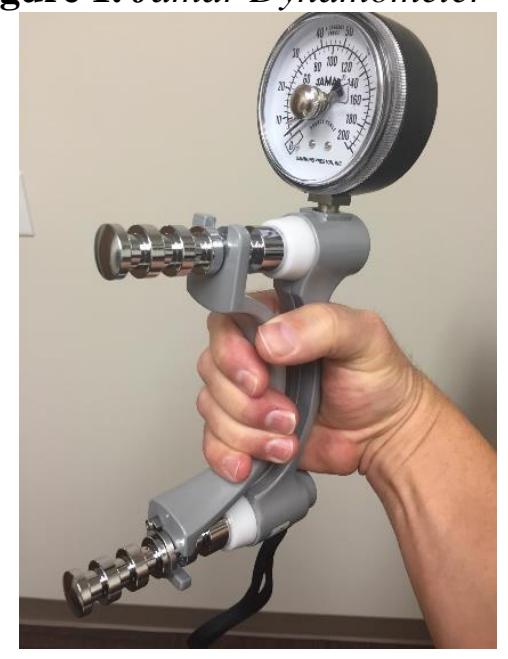

Figure 2. Racquetball Racket in Hand

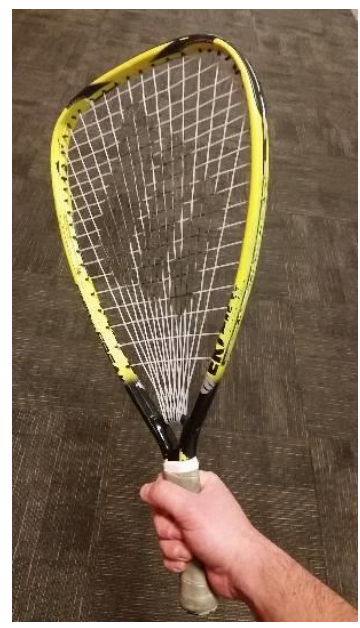

\section{Procedures}

Participants were seated or standing with the shoulder at $0^{\circ}$ abduction and $0^{\circ}$ flexion, while the elbow was at $90^{\circ}$ flexion, as recommended by American Society of Hand Therapists (Fess, 1992). The participants were instructed on proper technique (i.e. hand placement) for the grip strength measurements. The participants allowed to acquaint themselves with the Jamar (Figure 1. Note: the figure does not demonstrate the anatomical position during testing trials) by grasping and squeezing the Jamar prior to the execution of study trials. The participants were informed to execute a maximal grip effort for 3 seconds during the grip test trials. Verbal encouragement was provided by the test administrator to the participants during the tests trials. There was three trials of maximal grip collected with each trial separated by approximately 1-2 minutes. The greatest MG from the three trials was used for subsequent analysis. The 
MG trials were collected of the dominant hand only (the hand used to grip the racquet).

Each participant performed at least three trials. If a participant chose to perform more than three grip strength measurements, only the three highest readings were recorded for analysis (Mathiowetz, Weber, Volland, \& Kashman, 1984). After the data was collected, the participants' grip strength data was grouped according to the singles categories in which they competed, and then the participants proceeded to compete in the racquetball tournament. Under the structure of the Utah Summer Games Racquetball tournament, the players were grouped according to age (under 52, 55+, under 30, and 34+), gender (male and female), and skill level (Elite, B, C, and Open) and were therefore presumably competing with age, gender, and skill matched opponents. Only competitors in the singles tournament were included in this study. A typical racquet used in the USG tournament is pictured in Figure 2.

\section{Reliability}

Grip strength measurement was gathered using the Jamar Handgrip Dynamometer that has been demonstrated to be among the most accurate instruments for grip strength measurement (Mathiowetz et. al., 1984). Grip strength measurement is demonstrated to be most reliable when averaging of three maximal effort trials leading to correlation coefficients of 0.80 or higher (Mathiowetz et. al., 1984). The grip strength measures collected during the current study for trials 2 and 3 yielded a test re-test reliability coefficient of $\mathrm{r}=0.90$, considered very high (Safrit and Wood, 1995).

\section{Design and Analysis}

Success (final placement) in the racquetball tournament at the USG was broken down into two groups; $1^{\text {st }}$ place and those finished $2^{\text {nd }}$ or lower across competitive groups. The data were analyzed using an independent t-test comparing the average of three maximal grip strength tests of those who finished in $1^{\text {st }}$ versus those who finished in $2^{\text {nd }}$ place or lower. The statistical significance of this study was set at $p \leq 0.05$.

\section{Results}

The total number of participants whose data were analyzed is $n=20$. Descriptions of the participants in each competitive group are provided in Tables 1-8. 
Table 1. Elite Group Descriptive Information

\begin{tabular}{|l|l|l|l|}
\hline Participant Number & $\begin{array}{l}\text { Ave G.S. } \\
\text { (Newtons) }\end{array}$ & Age (years) & $\begin{array}{l}\text { End Tournament } \\
\text { Place }\end{array}$ \\
\hline 1 & $508.4 \pm 11.1$ & 41 & 3 \\
\hline 2 & $603.6 \pm 17.8$ & 50 & DNQ \\
\hline
\end{tabular}

$\mathrm{DNQ}=$ did not qualify for medal tournament; Age self-reported. G.S. =grip strength

Table 2. A Group Descriptive Information

\begin{tabular}{|l|l|l|l|}
\hline Participant Number & $\begin{array}{l}\text { Ave G.S. } \\
\text { (Newtons) }\end{array}$ & Age (years) & $\begin{array}{l}\text { End Tournament } \\
\text { Place }\end{array}$ \\
\hline 1 & $472.8 \pm 6.7$ & 47 & 1 \\
\hline 2 & $618.3 \pm 36.5$ & 45 & 2 \\
\hline 3 & $511.5 \pm 33.4$ & 56 & 3 \\
\hline 4 & $564.9 \pm 29.3$ & 37 & DNQ \\
\hline
\end{tabular}

$\mathrm{DNQ}=$ did not qualify for medal tournament; Age self-reported. G.S. =grip strength

Table 3. 50+ Group Descriptive Information

\begin{tabular}{|l|l|l|l|}
\hline Participant Number & $\begin{array}{l}\text { Ave G.S. } \\
\text { (Newtons) }\end{array}$ & Age (years) & $\begin{array}{l}\text { End Tournament } \\
\text { Place }\end{array}$ \\
\hline 1 & $363.4 \pm 16.9$ & 72 & 1 \\
\hline 2 & $446.1 \pm 24.5$ & 69 & 2 \\
\hline
\end{tabular}

$\mathrm{DNQ}=$ did not qualify for medal tournament; Age self-reported. G.S. =grip strength

Table 4. 50- Group Descriptive Information

\begin{tabular}{|l|l|l|l|}
\hline Participant Number & $\begin{array}{l}\text { Ave G.S. } \\
\text { (Newtons) }\end{array}$ & Age (years) & $\begin{array}{l}\text { End Tournament } \\
\text { Place }\end{array}$ \\
\hline 1 & $530.6 \pm 22.2$ & 36 & 1 \\
\hline 2 & $398.9 \pm 25.4$ & 38 & 2 \\
\hline 3 & $450.6 \pm 42.7$ & 46 & 3 \\
\hline 5 & $480.4 \pm 30.7$ & 44 & 4 \\
\hline 5 & $625.8 \pm 29.8$ & 42 & DNQ \\
\hline
\end{tabular}

$\mathrm{DNQ}=$ did not qualify for medal tournament; Age self-reported. G.S. =grip strength

Table 5. C Group Descriptive Information

\begin{tabular}{|l|l|l|l|}
\hline Participant Number & $\begin{array}{l}\text { Ave G.S. } \\
\text { (Newtons) }\end{array}$ & Age (years) & $\begin{array}{l}\text { End Tournament } \\
\text { Place }\end{array}$ \\
\hline 1 & $564.9 \pm 54.3$ & 35 & 1 \\
\hline 2 & $342.5 \pm 8.9$ & 57 & 2 \\
\hline 3 & $409.2 \pm 30.7$ & 31 & 4 \\
\hline
\end{tabular}

G.S. =grip strength 
Table 6. Open Group Descriptive Information

\begin{tabular}{|l|l|l|l|}
\hline Participant Number & $\begin{array}{l}\text { Ave G.S. } \\
\text { (Newtons) }\end{array}$ & Age (years) & $\begin{array}{l}\text { End Tournament } \\
\text { Place }\end{array}$ \\
\hline 1 & $564.9 \pm 0.0$ & 27 & 1 \\
\hline 2 & $551.5 \pm 31.1$ & 24 & 2 \\
\hline 3 & $603.6 \pm 24.5$ & 42 & 4 \\
4 & $471.5 \pm 34.7$ & 40 & DNQ \\
5 & $421.2 \pm 47.1$ & 42 & DNQ \\
6 & $564.9 \pm 11.6$ & 52 & DNQ \\
\hline
\end{tabular}

$\mathrm{DNQ}=$ did not qualify for tournament; Age self-reported. G.S. =grip strength

Table 7. Descriptive Information of Participants

\begin{tabular}{|l|l|l|}
\hline Group & $\mathrm{N}$ & Age (years) \\
\hline $1^{\text {st }}$ Place Finishers & 5 & $47.5 \pm 17.5$ \\
\hline $2^{\text {nd }}$ Place and Below & 15 & $46.3 \pm 10.9$ \\
\hline
\end{tabular}

The first place finisher's mean grip strength was $499.5 \pm 87.6$ Newtons. The mean grip strength of those who finished in second place and below was 497.3 \pm 84.9 Newtons. The independent t-test yielded a value of $p=0.48$, suggesting that there was no significant difference between the grip strength of those who finished in first place and those who finished in second place and lower.

Table 8. Normative Grip Strength (Newtons) Values for Males by Age Group for Jamar Dynamometer (Peters, et al., 2011) Versus Grip Strength Values from the Present Study

\begin{tabular}{|l|l|l|l|l|l|l|}
\hline $\begin{array}{l}\text { Age } \\
\text { years) }\end{array}$ & $20-29$ & $30-39$ & $40-49$ & $50-59$ & $60-69$ & $70-79$ \\
\hline $\begin{array}{l}\text { Peters, } \\
\text { et al., } \\
2011\end{array}$ & $444.8^{*}$ & $467.0^{*}$ & $475.9^{*}$ & $462.6^{*}$ & $422.6^{*}$ & $342.5^{*}$ \\
\hline $\begin{array}{l}\text { Present } \\
\text { Study }\end{array}$ & $576.0 \pm 11.1$ & $550.7 \pm 76.1$ & $518.2 \pm 77.8$ & $472.8 \pm 94.7$ & $446.1 \pm 0$ & $363.4 \pm 0$ \\
\hline
\end{tabular}

* No standard deviation values provided in the study

\section{Discussion}

The purpose of this study was to determine if grip strength had an influence on success in racquetball tournament play. The hypothesis of this study was that high grip strength would prove to be related to high placement in the USG tournament. The data recorded in this study supported the null hypothesis. Statistical analysis revealed that there was not a significant or practical difference between the grip strength of first place finishers and the other competitors.

In comparison to normative data available for the Jamar handgrip dynamometer, the grip strength measures reported in the current study were 
higher than the mean score for their age and gender matched groupings. Peters and colleagues (2011) reported mean values for grip strength using the Jamar grip dynamometer and those values are presented in Table 8 along with the grip strength measures collected in the present study. It is possible that the participants of the current study have higher grip strength than their peers due to their regular participation in racquetball, a notion that could be determined in future research efforts. With that said, prior studies examining the grip strength of other racquet sports players is reasonably consistent with the current study. Davey (2002) reported the grip strength of elite male tennis players to be $509 \mathrm{~N}$. Likewise, Todd and Mahoney (1995) recorded grip strength measures of approximately $500 \mathrm{~N}$ for elite male squash players. The results of the aforementioned studies (Davey, 2002; Todd \& Mahoney, 1995) and the current study seem to corroborate the notion that regular participation in racquet sports leads to increased grip strength.

This study is significant because to the knowledge of the authors it is the first to investigate the relationship between grip strength and racquetball performance in a tournament setting. Previous research has shown that grip strength had a positive effect in baseball with post impact ball velocity (Missavage et al., 1984). Additionally, Elliot (1982) found a positive influence of grip tightness on post impact ball velocity in racquetball. Because of the important role ball velocity plays in the game of racquetball and the possible relationship between grip strength and ball velocity, it seems reasonable that a player with a stronger/tighter grip might have a competitive advantage over one who has a weaker grip.

Grip strength has been demonstrated to correlate strongly with many fitness and performance measures such as body composition, energy expenditure, aerobic power, lower limb strength, speed, flexibility, functional body movements and agility (DeBeliso et al., 2015; DeBeliso et al., 2015; Rodrigues Matsudo, et al., 2015). All of these measures play an obvious role in sports performance, and indeed research has found correlations between grip strength and performance in a variety of sports including swimming (Garrido et al., 2012), wrestling (Pallarés, López-Gullón, Torres-Bonete, \& Izquierdo, 2012) and luge (Platzer, Raschner, \& Patterson, 2009).

Grip strength has proven to play a significant role in the development of one of the most common injuries suffered by racquetball players, lateral epicondylitis or "tennis elbow" ball (King, Kentel, \& Mitchell, 2012). Some research has indicated that an excessively tight grip might put the racquetball athlete at a higher risk of developing lateral epicondylitis (King et al., 2012). Other research has indicated that a weak or lax grip of the racquet handle also correlates with the development of the very same injury (Khan \& Mahajan, 2013). Still other research has proposed that other factors such as the size and shape of the racquet handle play a bigger role in the development of lateral epicondylitis (Rossi, Vigouroux, Barla, \& Berton, 2014). It is possible that manipulation of racquet grip size and shape could help mitigate the role that grip tightness plays in the development of tennis elbow. 
The importance of grip strength in sports played with a racquet is amplified because of the involvement of the hand in controlling of the racquet. In tennis, it has been suggested that although grip strength did not directly affect the post impact velocity of the ball, that grip strength is important to control of the racquet both before and after the ball is struck, especially when the impact of the ball with the racquet is off center (Grabiner, Groppel, \& Campbell, 1983). The tightness of a racquetball player's grasp on the racquet has a direct effect on the rotation of the racquet (i.e. position of the racquet in the hand) before, during, and after impact with the ball (King et al., 2012). Control of the racquet in the time leading up to and maintenance of control after the moment the ball is impacted are of the utmost importance to successful performance in racquet sports (Elliot, Kotaro, \& Guillermo, 1997), as this racquet control can influence the precision of ball placement and ball spin. A strong grip will influence a racquet sport athlete's ability to maintain adequate control of the racquet before and after striking the ball. With that said, the current study did not demonstrate that grip strength and its potential relationship to racquet control effected tournament placement.

We did not attempt to assess grip endurance in the current study. It is possible that measuring grip endurance may have led to a different study outcome. With that said, Kramer and Knudson (1992) suggested that maximal grip force was fatigue resistant in their study sample of female and male college tennis players. Although the Kramer and Knudson study was conducted with a different racquet type sport, we felt comfortable with our study focus on maximal grip strength (and not endurance) as being primarily associated with successful racquetball tournament play.

The most obvious limitation of the current study is the relatively small number of participants. The limited amount of analyzable data for this study restricted the researcher's ability to evaluate the relationship between grip strength and racquetball performance. Another possible limitation is the level of play at the racquetball tournament at the USG. All participants in the USG tournament were amateur racquetball players, so no elite racquetball performances were analyzed in this study. Because of the amateur nature of the tournament, it is likely that the skill level of individual players varied widely. Finally, the inability to control various influential factors and conditions (i.e. years of playing experience, altitude acclimatization, racquet handle covering, and general fitness level, etc.) is an inherent limitation of this study.

Racquetball training theory does not currently place a high degree of importance on the development of grip strength, albeit many of the resistance exercises (forearm curls, seated pulley rows, dumbbell exercises, etc.) suggested as part of a training regimen for racquetball do either directly or indirectly improve grip strength (Moran \& MacGlynn, 1997). The findings of the current study did not demonstrate evidence to suggest a departure from the current theory regarding racquetball training and the low emphasis placed on grip strength training.

Given the fact that grip strength and post impact ball velocity are positively correlated in racquetball (Elliot, 1982) and the role grip strength 
plays in the manipulation and maintenance of racquet position (King et al., 2012) it stands to reason that having a tighter grip might be advantageous in certain circumstances often faced in racquetball. Examples of such circumstances include but are not limited to serving, returning, hitting the ball off the back wall, and striking when the body is in a position that is not optimal for ball striking. In all of these circumstances, the added velocity and/or racquet control due to a stronger grip could play a significant role in the outcome of the volley and ultimately the game.

Because of the findings of this study, it is not suggested that racquetball players dedicate extra time to grip strength training until future research clarifies the relationship between grip strength and racquetball performance. Instead, players should focus on gaining experience and improving skill level, as it is possible that these factors bear a greater influence on racquetball performance and success. Conversely, resistance training exercises scheduled to improve grip strength are easy to perform and do not require special equipment. Dynamic grip strength or "crush strength" training could be conducted using a racquetball as a modality and simply squeezing the ball for multiple repetitions. "Isometric" grip strength could be conducted by simply using the racquet handle as the exercise modality and squeezing it. Finally, "breakaway grip strength" (eccentric failure of the hand grasping an implement) could be resistance trained by holding on to a pull-up bar (holding one's body weight). Each of these grip exercise modalities could be scheduled within a periodized training protocol that would require little time or specialized equipment.

Although the current study did not find grip strength to be influential on racquetball performance, further research is needed on the topic. As stated previously in this article, research by Elliot (1982) has shown that grip strength influences post impact ball velocity in racquet sports played with a short racquet. Future research should explore the relationship between grip strength, ball velocity and racquetball performance in further detail. For example, an alternate instrument to measure grip strength such as the GripForce Map system might provide the specificity and resolution required to identify what aspects of grip strength might play a greater role in racquetball performance (DeBeliso, McChesney, \& Murdock, 2013). Future research should also attempt to replicate the current study analyzing elite level racquetball players. It is possible when all competitors are matched for skill level (elite), a factor such as grip strength may exhibit a greater influence on tournament performance than it did in the amateur tournament at the USG.

\section{Conclusion}

Within the context of this study, grip strength does not appear to influence racquetball performance in a tournament setting. The results of the study appear to be in conflict with the results of previous research examining the role of grip strength and sport performance where there is a need for the hand to 
grip a sport implement. As such, we recommend that future research should be carried out with alternative grip assessment instruments, differing participant populations, larger participant pools (n), examination of the role of grip strength and racquet control including post racquet impact velocity, and varying racquet grip types (size, shape, firmness, and texture).

\section{References}

Amaral, J.F., Mancini, M., \& Novo Júnior, J.M. (2012). Comparison of three hand dynamometers in relation to the accuracy and precision of the measurements. Brazilian Journal of Physical Therapy, 16(3), 216-224.

Davey, P.R. (2002). Grip strength/endurance testing of elite tennis players versus nonracket players. In Proceedings of the 7th Annual Congress of the European College of Sports Science, p. 1115. Athens: Paskalidis Medical Publishers.

DeBeliso, M., McChesney, J., \& Murdock, L. (2013). Grip norms and reliability of the hand grip ForceMap system. Journal of Hand Surgery, European Volume, 6, 4-7.

DeBeliso, M., Boham, M., Harris, C., Carson, C., Berning, J.M., Sevene, T.G., \& Adams, K.J. (2015). Grip and body strength measures in the mature adult: A brief report. International Journal of Science and Engineering Investigations, 4(37), 83-86.

DeBeliso, M., Boham, M., Harris, C., Carson, C., Berning, J.M., Sevene, T.G., Adams, K.J., \& Climstein, M. (2015). Grip strength and functional measures in the mature adult: Brief report II. International Journal of Science and Engineering Investigations, 4(39), 1-4.

Elliott, B. (1982). Tennis: the influence of grip tightness on reaction impulse and rebound velocity. Medicine \& Science in Sports \& Exercise, 14(5), 348-352.

Elliot, B., Kotaro, T., Guillermo, N. (1997). The influence of grip position on upper limb contributions to racket head velocity in a tennis forehand. Journal of Applied Biomechanics, 13, 182-196.

Fess, E.E. Grip strength. In: Casanova, J.S. (Ed.) Clinical assessment recommendations, $2^{\text {nd }}$ Ed. Chicago, American Society of Hand Therapists, 1992: 41-5.

Garrido, N.D., Silva, A.J., Fernandes, R.J., Barbosa, T.M., Costa, A.M., Marinho, D.A., \& Marques, M.C. (2012). High level swimming performance and it's relation to non-specific parameters: a cross-sectional study on maximum handgrip isometric strength. Perceptual \& Motor Skills, 114(3), 936-948.

Grabiner, M., Groppel, J., \& Campbell, K. (1983). Resultant tennis ball velocity as a function of off-center impact and grip firmness. Medicine \& Science in Sports \& Exercise, 15(6), 542-544.

Khan, T., \& Mahajan, S. (2013). Effect of different arm and forearm positions on grip strength. International Journal of Sports Sciences \& Fitness, 3(2), 259-269.

King, M.A., Kentel, B.B., \& Mitchell, S.R. (2012). The effects of ball impact location and grip tightness on the arm, racquet and ball for one-handed tennis backhand groundstrokes. Journal of Biomechanics, 45(6), 1048-1052.

Koley, S., \& Yadav, M.K. (2009). An association of hand grip strength with some anthropometric variables in Indian cricket players. Facta Universitatis: Series Physical Education \& Sport, 7(2), 113-123.

Kramer, A.M., \& Knudson, D.V. (1992). Grip strength and fatigue in junior college tennis players. Perceptual and Motor Skills, 75, 363-366. 
Mathiowetz, V., Weber, K., Volland, G., \& Kashman, N. (1984). Reliability and validity of grip and pinch strength evaluations. Journal of Hand Surgery (03635023), 9(2), 222-226.

Missavage, R., Baker, J., \& Putnam, C. (1984). Theoretical modeling of grip firmness during ball-racket impact. Research Quarterly for Exercise \& Sport, 55(3), 254-260.

Moran, G.T., \& MacGlynn, G.H. (1997). Chapter 31: Racquetball, Handball, and Squash. Cross-Training for Sports (pp. 220-224).

Pallerés, J.G., López-Gullón, J.M., Torres-Bonete, M.D., \& Izquierdo, M. (2012). Physical fitness factors to predict female Olympic wrestling performance and sex differences. Journal of Strength \& Conditioning Research, 26(3), 794-803.

Peters, M.H., Van Nes, S.I., Vanhoutte, E.K., Bakkers, M., Van Doorn, P.A., Merkies, I.J., \& Faber, C.G. (2011). Revised normative values for grip strength with the Jamar dynamometer. Journal of the Peripheral Nervous System: JPNS, 16(1), 4750. doi:10.1111/j.1529-8027.2011.00318.x

Platzer, H., Raschner, C., \& Patterson, C. (2009). Performance-determining physiological factors in the luge start. Journal of Sports Sciences, 27(3), 221-226.

Rodrigues Matsudo, V.K., Matsudo, S.M., de Rezende, L.M., \& Raso, V. (2015). Handgrip strength as a predictor of physical fitness in children and adolescents. Brazilian Journal of Kineanthropometry \& Human Performance, 17(1), 1-10.

Rossi, J., Vigouroux, L., Barla, C., \& Berton, E. (2014). Potential effects of racket grip size on lateral epicondilalgy risks. Scandinavian Journal of Medicine \& Science in Sports, 24(6), e462-470.

Safrit, M.J., \& Wood, T.M. (1995). Introduction to measurement in physical education and exercise $\left(3^{\text {rd }}\right.$ Ed.). St. Louis, MO: Mosby.

Todd, M.K., \& Mahoney, C.A. (1995). Determination of pre-season physiological characteristics of elite male squash players. In Science and Racket Sports (edited by T. Reilly, M. Hughes and A. Lees), pp. 81-88. London: E \& FN Spon.

Weyrich, A., Messier, S., Ruhmann, B., \& Berry, M. (1989). Effects of bat composition, grip firmness, and impact location on post impact ball velocity. Medicine \& Science in Sports \& Exercise, 21(2), 199-205. 
